\title{
A QUESTÃO "HOMEM" COMO PROBLEMA FUNDAMENTAL DA FILOSOFIA NA PERSPECTIVA DE MAX SCHELER
}

\author{
The Issue "Man" as a Fundamental Problem \\ of the Philosophy in the Perspective of Max Scheler
}

Soter Schiller ${ }^{1}$

\begin{abstract}
RESUMO: Antropologia Filosófica hoje: uma proposta de resgatar a identidade do homem, no contexto cultural contemporâneo. Da fenomenologia da vida para a fenomenologia do "espírito" que, no pensamento de Scheler, identifica a essencialidade do homem. As peculiaridades do "espírito": o "poder de objetivação", de "ideação", a "pura atualidade", liberdade e autonomia existencial, a consciência do absoluto.
\end{abstract}

PALAVRAS-CHAVE: Max Scheler; Antropologia Filosófica; Homem; Fenomenologia; Espírito.

ABSTRACT: Philosophical Anthropology today: a proposal to recover the human identity in the contemporary cultural context. From the phenomenology of life to a phenomenology of "spirit", which, according Max Scheler, identifies the essentiality of man. The peculiarities of "spirit": the "power of objectivation", of "ideation", the "pure actuality", liberty and existential autonomy, the consciousness of the absolute.

KEYWORDS: Max Scheler; Philosophical Anthropology; Man; Phenomenology; Spirit.

Max Scheler, um filósofo identificado com a vertente personalista da fenomenologia, vai paulatinamente tomando consciência de que é necessário a filosofia fazer uma conversão ao tema do homem. São as circunstâncias históricas contemporâneas que, a seu ver, interpelam uma renovada consciência, no intuito de promover a "salvação" do homem frente às ameaças que vão progressivamente se avolumando: os conflitos mundiais (ele viveu o primeiro), as condições da sociedade industrial, as ideologias que desvirtuam a consciência da identidade humana, positivismo, materialismos, naturalismos... A isso concorrem as ciências ditas "humanas" que, desde a segunda

\footnotetext{
${ }^{1}$ Mestre em teologia pelo Pontificio Ateneo di Sant'Anselmo, Roma, Itália, e professor de filosofia na Faculdade São Basílio Magno (FASBAM). E-mail: soschill@hotmail.com
} 
metade do século XIX produziram um grande cabedal de dados e fatos relativos à ciência das humanidades, mas perderam a chave de interpretação do ser humano.

É sobretudo a partir da fenomenologia e também das temáticas do existencialismo que o tema da existência vai se convertendo na questão da essência da natureza humana. Ou seja, da fenomenologia renasce a perspectiva metafísica do ser, mais particularmente uma metafísica do homem, centrada na questão “quem é o homem?", na busca de uma compreensão do ser humano sob um ponto de vista global, essencialista, projetando a definição do lugar do homem na constelação dos seres.

Já Kant tinha se dado consciência, ainda no século XVIII, de que a questão antropológica ocupava lugar preeminente entre todas as questões filosóficas, que era a mais importante delas, e à qual convergem todas as demais questões que se podem pôr em especulação filosófica. É verdade que o lema socrático - "conhece-te a ti mesmo" tinha saído fora de foco na babilônia filosófica moderna e era preciso reconduzi-la à prioridade. "Quem é o homem?" - eis a questão das questões, segundo Kant, à qual convergem as perguntas capitais que podem ser feitas no contexto da filosofia. As perguntas “Que posso saber? Que devo fazer? Que me é permitido esperar?”2 explicitam, no fundo, a questão-homem, sua identidade, sua natureza. Kant intuiu que o lema socrático deveria ser o foco nuclear da especulação filosófica, embora a sua projetada “antropologia” não tenha vindo à luz.

A questão do homem, segundo Scheler, deve ser, então, recolocada como a questão central e convergente de toda a filosofia. Declara ele: "Desde o primeiro despertar da minha consciência filosófica, as perguntas: o que é o homem e qual a sua posição no interior do ser me ocuparam mais essencialmente do que qualquer outra pergunta filosófica"3.

$\mathrm{Na}$ verdade, o interesse pela questão antropológica perpassa toda a carreira de Scheler, particularmente desde a sua adesão à fenomenologia (1914), que se materializa em suas obras, ensaios e artigos ${ }^{4}$, como também em suas preleções na Universidade de Colônia, e se tornou mais premente, quase uma paixão, no final de sua vida. Pôde ele, então, constatar que a questão "constituição essencial do homem" ascendia no meio filosófico à posição de supremacia:

\footnotetext{
${ }^{2}$ KANT, Immanuel. Crítica da Razão Pura, Cap. II, Secção II.

${ }^{3}$ SCHELER, M. A Posição do Homem no Cosmos. Título original: Die Stellung des Menschen im Cosmos de 1928. Rio de Janeiro: Ed. Forense Universitária, 2003, p. 3

${ }^{4}$ Cf. p.ex. Do Eterno no Homem (1922); O Homem e a História (1926); a conferência O Lugar peculiar do Homem ...
} 
Tenho a satisfação de constatar que os problemas de uma antropologia filosófica ganharam hoje o ponto central de toda a problemática filosófica na Alemanha e que, muito além do círculo dos especialistas em filosofia, há biólogos, médicos, psicólogos e sociólogos trabalhando em uma nova imagem da constituição essencial do homem .

Scheler constata que a tradição filosófica no tocante à compreensão do homem encontra um fator que pede passagem para entrar em seu caminho: são as ciências ditas "humanas", que desde o Positivismo do século XIX vão se afirmando no cenário da história das ideias. No entanto, paradoxalmente, essa aparente riqueza de dados e fatos referentes ao fenômeno humano, provida pela ciência biológica, sociológica, psicológica e outras mais, não resultou em um autoconhecimento do homem mais profundo e mais esclarecido. Pelo contrário, a "confusão de línguas" se estendeu mais ainda. E o acúmulo de dados não importou em um aumento de conhecimento. A dissolução da filosofia especulativa desde a última metade do século XIX, magistralmente descrita por Karl Löwith ${ }^{6}$, leva a uma consciência de insatisfação e desorientação que se pode identificar na perda de algo capaz de dar rumo e sentido à vida. A situação é paradoxal: temos um corpo amplíssimo de conhecimentos sobre o homem, procedentes dos mais heterogêneos lugares, porém completamente sem comunicação entre si. Não é que falte uma ideia do homem, mas que ela são várias e múltiplas que se ignoram mutuamente e não sabem aproveitar o que de valioso oferecem umas às outras. É o que constata igualmente Heidegger:

Nenhuma época teve noções tão variadas sobre o homem como a atual. Nenhuma época conseguiu, como a nossa, apresentar o seu conhecimento sobre o homem de modo tão eficaz e fascinante, nem comunicá-lo de modo tão fácil e rápido. Mas também é verdade que nenhuma época soube menos que a nossa sobre o que é o homem. Nunca o homem assumiu um aspecto tão problemático como atualmente ${ }^{7}$.

Semelhante conclusão faz o próprio Scheler:

Os problemas que o homem coloca acerca de si mesmo alcançaram no presente o ponto máximo registrado em toda a história que nos é conhecida. No momento, como o homem admitiu nunca ter estado antes com uma posse tão diminuta de um saber rigoroso sobre o seu ser e nenhuma possibilidade de resposta a esta pergunta o assusta mais a nova coragem para a veracidade parece ter retornado até ele $e^{8}$.

Circunstâncias históricas que marcaram os tempos contemporâneos, desde a Revolução Industrial, o embate capitalismo x socialismo, os confrontos ideológicos, os

\footnotetext{
${ }^{5}$ SCHELER, M. op. cit., 2003, p. 3.

${ }^{6}$ LÖWITH, Karl. De Hegel a Nietzsche. 2. ed. Buenos Aires: Editorial Sudamérica, 1974.

${ }^{7}$ HEIDEGGER, M. Kant y el problema de la metafísica. Mexico: Fondo de Cultura Económica, 1986, p. 177.

${ }^{8}$ SCHELER, M. op. cit., 2003, p. 3.
} 
conflitos mundiais, o fenômeno da sociedade global, a fusão das culturas e tantas mais impulsionaram reflexões, ideias e movimentos de defesa e de salvação do ser de sua própria degradação e perda de sua identidade, e mesmo de sua extinção. São os movimentos filosóficos e culturais que já desde o início do século XX se centram na questão humana, na recuperação de uma "antropologia", como o existencialismo, a fenomenologia, o personalismo e entidades afins.

Sobretudo um particular círculo de literatos, surgido ainda na primeira metade do século XX, que foi apropriadamente chamado de "movimento Antropologia Filosófica", pretendia impor uma guinada humanística à cultura contemporânea, inspirar enfoques metafísicos à compreensão da essencialidade humana, da identidade fundamental do homem, sua tarefa no mundo dentro do conjunto dos seres e seu destino final.

Muito identificada com a "busca das essências" da fenomenologia e investida de viés personalista, a "antropologia filosófica" - a denominação é de Ernst Cassirer (1944) impulsionada pela pequena, mas densa, obra "A Posição do Homem no Cosmos" de Max Scheler, do ano de 1928. Aponta ele os objetivos do escrito:

No momento, como o homem admitiu nunca ter estado antes com uma posse dão diminuta de um saber rigoroso sobre o seu ser e como nenhuma possibilidade de resposta a esta pergunta o assusta mais, a nova coragem para a veracidade parece ter retornado até ele: a coragem de colocar de uma maneira nova esta questão essencial, ... a coragem de desenvolver - aproveitando ao mesmo tempo os ricos tesouros de saber conquistados através das diversas ciências do homem - uma nova forma de sua autoconsciência e de sua auto-intuição" 10 .

De imediato, a ideia e o movimento concebido por Scheler recebeu múltiplas adesões. Já em 1928, Arnold Gehlen publicava O Homem, sua Natureza e seu Lugar no Mundo, seguido por Helmuth Plessner (Os Estofos do Orgânico e o Homem - 1928), Nicolai von Hartmann (O Problema do Ser Espiritual - 1931), A. Portmann (Biologia e Espírito 1940), E. Rothaker (Antropologia Filosófica - 1953) ${ }^{11}$. A estes se juntam os teóricos do "Personalismo": E. Mounier (O Personalismo - 1950), J. Lacroix (Pessoa e Amor 1942), M. Nédoncelle (Pessoa Humana e Natureza - 1943 e outros. Até um neokantiano como Ernst Cassirer publicou uma obra à qual pôs por primeiro o título de "Antropologia Filosófica" (1944).

As considerações de Max Scheler em torno do assunto "antropologia filosófica" se concentram na obra mencionada - cujo título original talvez fosse melhor traduzido como "O Lugar do Homem no Mundo" - que veio à luz a partir de uma conferência pronunciada

\footnotetext{
${ }^{9}$ SCHELER, M. op. cit., 2003, p. 3.

${ }^{10} \mathrm{Id}$.

${ }^{11}$ Citamos os títulos em português, mas nem todas essas obras existem tradução portuguesa.
} 
em Darmstadt em abril de 1927 com o título de $A$ posição peculiar do homem, que suscitou um grande interesse sobre esse "grandioso objeto", como ele diz. $\mathrm{Na}$ A Posição do Homem no Cosmos confluem considerações tratadas em outras obras suas, desde o ensaio Para a Ideia do Homem (1923), passando por Do Eterno no Homem (1924), O Homem e a História (1926), referindo-se mesmo a aspectos elaborados no clássico $O$ Formalismo na Ética e Ética Material dos Valores (1913/1916), sempre objetivando a questão que cada vez mais concentrava seu interesse: o que é o homem e qual o seu lugar no interior do ser? ${ }^{12}$

A Posição do Homem no Cosmos leva a marca da sua adesão à Fenomenologia husserliana que busca a descrição e diferenciação dos phenomena vitais no mundo e pretende esclarecer a relação entre "vida" e "espírito", abrigando uma preocupação essencialista ou de identificação do que é especificamente e inequivocadamente humano. Isso numa época de crescente redução positivista e materialista do ser humano.

A preocupação fundamental de Scheler é construir uma tentativa de superar a confusão de ideias sobre o homem. O termo e o conceito de 'homem' contêm uma ambiguidade insidiosa $^{13}$, e por conseguinte não possuímos uma ideia una do homem ${ }^{14}$. Na cultura ocidental se entrelaçam e se confrontam três ideias aparentemente inconciliáveis: a judaico-cristã, que concebe o homem como dotado de uma natureza originada por criação divina, mas posteriormente uma natureza "decaída", necessitada de ser "salva"; a filosofia clássica de origem grega que vê o homem como determinado pela posse do logos, frónesis, ou ratio; e a imagem produzida pela ciência moderna que apresenta o homem como o resultado final e tardio da evolução da vida no planeta terra.

É justamente a visão do homem a partir da ciência biológica que prevalece hoje sobre as demais: o homem é uma forma de vida mais evoluída, o ponto convergente da evolução. Convergiram nesse ponto de vista o darwinismo, as teorias de evolução, o materialismo dialético, a genética moderna, os estudos sobre o cérebro e mente e todos os demais ramos da ciência biológica e algumas correntes da psicologia contemporânea, firmando a conclusão de que a evolução da vida no universo chegou a seu ponto convergente, e talvez final, produzindo sua obra mais acabada, o homem.

O livrinho de Scheler tem, pois, o intuito de verificar os resultados alcançados pela biologia na primeira metade do século $\mathrm{XX}$, para concluir que o homem não pode ser

\footnotetext{
${ }^{12}$ SCHELER, M. op. cit., 2003, p. 1.

${ }^{13}$ Ibid., p. 6.

${ }^{14}$ Id.
} 
pensado simplesmente a partir dos resultados da ciência, de ser ele apenas uma estrutura biológica, a forma máxima de vida no universo. A sua "posição no cosmos" necessita de uma extensão para o interior de uma experiência diversa, a metafísica ${ }^{15}$, ou seja, a nossa compreensão do homem não se finaliza no nível científico, seja biológico seja psicológico, mas clama por uma fundamentação mais consistente, a metafísica.

Numa primeira parte da A Posição do Homem no Cosmos, Scheler analisa os diversos graus de vida, desde o "impulso afetivo" (Drang) que caracteriza as plantas, passando pelo "instinto" (insetos), "memória associativa" (vertebrados), até à inteligência prática", definida pela capacidade de fazer escolhas, uma inteligência essencialmente orientada à sobrevivência no meio vital que caracteriza os mamíferos superiores e os primatas. As formas de vida se definem, enfim, pela sua vinculação e dependência do meio em que vivem.

O homem seria também incluído nesse último estágio de "vida"? Ou seja, o homem seria o derradeiro produto da evolução da vida e sua natureza específica se definiria por um grau mais sofisticado ainda de inteligência? Scheler contesta essa visão da natureza essencial do homem:

Eu sustento que a essência do homem e isto que se pode chamar a sua 'posição peculiar' encontramse muito além do que se denomina inteligência e capacidade de escolha, e que elas tampouco seriam alcançadas se se representasse esta inteligência e capacidade de escolha de uma maneira quantitativa qualquer, sim, projetada até ao infinito ${ }^{16}$.

Quer dizer: não é a inteligência que define a natureza específica do homem, por maior grau que ela seja projetada. Para quem se contrapusesse a essa afirmação, a diferença entre um chimpanzé e Thomas Edison seria apenas gradual. Para Scheler é equivocado situar simplesmente na esfera vital e psíquica, cujo conhecimento cairia sob a única competência da psicologia e biologia ${ }^{17}$. Ele decididamente situa o homem para além do princípio da "vida": O que torna o homem ... não é um novo estágio da vidal.

Que coisa, que elemento define, então, a especificidade e a originalidade do homem no contexto dos seres no mundo? Que palavra pode expressar esse elemento? Resposta: uma palavra que certamente abarca (a natureza especifica do homem) ... é a palavra espírito $^{19}$.

\footnotetext{
${ }^{15}$ SCHELER, M. op. cit., 2003, p. 6.

${ }^{16}$ Ibid., p. 35.

${ }^{17} \mathrm{Id}$.

${ }^{18} \mathrm{Id}$.

${ }^{19}$ SCHELER, M. op. cit., 2003, p. 35.
} 
"Espírito" é, pois o termo que abrange todos os atributos e a própria essencialidade do homem, que inclui a razão, a "intuição", a vontade e as emoções, cujo centro ativo designamos com a palavra "pessoa"20. O termo "espírito", em paridade com "pessoa", expressa cabalmente o núcleo significante do ser humano, designando o que lhe é próprio, colocando-o assim no vértice dos seres no mundo, mas atribuindo-lhe uma diferença essencial.

"Espírito" - perguntemo-nos aqui - mas por que não "alma", o princípio que, segundo a tradição da filosofia clássica, de molde aristotélico-tomista, define a especificidade do homem? Na filosofia grega e na escolástica cristã medieval, se entendeu "alma" como "princípio da vida", aquilo (a "forma") que confere propriedades vitais a um ser num escalonamento de três graus: vegetativo, sensitivo e intelectivo. A alma fundamenta as atividades espirituais em conjunto com os atos biológicos e sensoriais. Com isso, a filosofia clássica insere o homem, definido pela sua alma intelectiva (animal rationale), na naturalidade do mundo. Ele é um ser natural, parte integrante dos escalões da natureza - e não está fora dela - embora ocupando o mais alto grau entre os seres naturais.

Será que o que Scheler fala sobre "espírito" não está incluído no conceito clássico de "alma espiritual", suas potencialidades, expressas nas chamadas "faculdades" da alma? Ele faz uma crítica da teoria clássica do homem, na qual o conceito de alma fica comprometido com a sua categorização como "substância", crítica semelhante à de Hume $^{21}$. O ponto de divergência está nisso que Scheler contrapõe "espírito" a qualquer manifestação ou grau de vida; não é sequer o mais alto grau de vida. O conceito de "espírito" comporta: "Seu desprendimento existencial do orgânico, sua liberdade, sua separabilidade - ou a menos a separabilidade de seu centro existencial - ante os laços, a pressão e a dependência do orgânico, da vida e de tudo o pertence à vida"22.

Parece-nos que com essa afirmação - a "separabilidade" do espírito em relação à vida - a unidade humana tão solidamente fundamentada na doutrina hilemórfica de Aristóteles e pela "união substancial” de São Tomás de Aquino, fica decididamente comprometida. Ainda que Scheler afirme a coerência entre as várias dimensões do homem, com a desvinculação entre o "espírito" e o biológico resulta uma visão fragmentada ou mesmo dualista do ser humano, um retorno ao problema cartesiano. Pois justamente na doutrina

\footnotetext{
${ }^{20}$ Ibid., p. 36.

${ }^{21}$ Cf. Ibid. p. 54-78, onde ele desenvolve essa crítica à "teoria clássica" e a outras doutrinas, sobretudo, as "naturalistas" sobre conceitos antropológicos.

${ }^{22}$ Ibid., p. 36.
} 
antropológica clássica o "espírito" ou "alma espiritual" é aquilo que "in-forma" e "atualiza" todos os estratos ou dimensões do homem. Neste sentido, todos os atos humanos são simultaneamente físico-biológico-espirituais. Digamos assim: os atos espirituais, de caráter racional ou emocional, ainda que plenamente tipificados, levam a marca do físico e do biológico e, inversamente, o físico e o biológico são sempre afetados pelo espiritual. Nicolai von Hartmann, na sua obra O Problema do Ser Espiritual (1931) apresenta de maneira perspicaz o conceito do homem como "unidade pluridimensional", em que as diversas dimensões do homem - físico, biológico, psíquico e espiritual - pelo fato de que uma dimensão é o "substrato" de outra superior, evidenciam a unidade "pluridimensional" do homem.

Apesar dessas complicações, Scheler faz uma brilhante fenomenologia do "espírito", caracterizando seus atos peculiares e essenciais. Na verdade, ele não se detém propriamente em explicar a unidade humana (e não a nega), mas se centra no identificar o proprium humano, caracterizar o diferencial humano, distinguindo-o de toda a linhagem animal, situando-o no topo da hierarquia dos seres no mundo.

Seguindo o seu pensamento, podemos então identificar e descrever fenomenologicamente as "características" ou notas essenciais do ser humano: são as "peculiaridades humanas" 23 que ele destaca no cerne de A Posição do Homem no Cosmos:

a) Em primeiro lugar, o espírito se caracteriza pelo "poder de objetivação" (Sachlichkeit). O animal é incapaz de estabelecer uma distância entre si e os objetos; ele se comporta "estaticamente" em relação ao meio em que vive; as coisas do mundo se referem diretamente aos seus instintos.

"Eu diria que o animal é, por essência, preso à realidade vital, que corresponde aos seus estados orgânicos, está engajado nela, sem jamais poder apreendê-la objetivamente" 24 .

O animal, na verdade, não tem “objetos”, as coisas são para ele como que extensões dele mesmo. O homem, porque espírito, é capaz desse recuo frente às coisas, é capaz de um comportamento objetivo. Ser-objeto é, portanto, a categoria mais formal do aspecto lógico do "espírito"25.

Por conseguinte, o animal tem um "meio" (Umwelt), está preso a ele, está em relação de dependência do ambiente. Já o homem, diz Scheler, possui um "mundo"

\footnotetext{
${ }^{23}$ Cf. Ibid., p. 44.

${ }^{24}$ Ibid., p. 40.

${ }^{25}$ SCHELER, M. op. cit., 2003, p. 38.
} 
(Welt): todas as coisas ao seu redor são objetos de seu conhecimento (ciência), sua ação (trabalho, técnica...). O homem emerge nitidamente de seu meio. Por isso mesmo, o homem se caracteriza também como "autoconsciência", isto é, pode objetivar, além do mundo, também a si mesmo, fazer de si mesmo um objeto. "Autoconsciência", o "sei que sei", é o que falta ao animal.

O animal tem consciência, diferentemente das plantas, mas não tem nenhuma autoconsciência, como já o vira Leibniz. Ele não possui a si mesmo, não detém o poder sobre si mesmo - e por isso também não é consciente de si. Reunião, autoconsciência e capacidade objetiva de resistência pulsional originária formam uma única estrutura ilacerável que, como tal, só é própria do homem ${ }^{26}$.

b) A forma superior da capacidade objetiva é o "poder de ideação"27. "Ideação" é propriamente a capacidade de pensar. Com isso, a inteligência humana se distingue essencialmente da inteligência animal Seus poderes são muito superiores à inteligência animal. A "ideação" é poder de lidar só com ideias como substitutas dos objetos, o poder de converter os objetos em ideias. É nada mais que aquilo que São Tomás denominou "abstração" e Ernst Cassirer denominou "poder simbolizador" ${ }^{28}$. Eu posso falar de ursos, sem me referir a nenhum urso em particular e sem ter algum à minha frente. "Ideação", como a concebe Scheler "não é outra coisa que conhecimento da essência" ${ }^{29}$, segundo o modo de falar da fenomenologia ou também, como diz Scheler, é a capacidade de fazer a cisão entre essência e existência ${ }^{30}$, quer dizer, distinguir essência da existência.

Idear significa apreender as propriedades e as formas constitutivas essenciais do mundo, independentemente da dimensão e do número de observações que fazemos e dos raciocínios indutivos, tais como a inteligência as coloca, e sobre um único exemplo da região interessada ${ }^{31}$.

Enfim, o "poder de ideação" significa a capacidade de formar ideias abstratas, estabelecer relações entre ideias, e manejar com elas. Esta capacidade do espírito confere ao homem um extraordinário poder de construir um mundo ideal através da cultura, ciência, arte, metafísica, religião - capacidade que, por sua vez, confere ao homem o poder de dominar e mesmo mudar o mundo real.

c) O "espírito" é "pura atualidade":

O espírito é o único ser incapaz de ser objeto; é atualidade pura; seu ser se esgota na livre realização de seus atos. O ser do espírito, a pessoa, não é, portanto, nem ser substancial nem

${ }^{26}$ Ibid., p. 39.

${ }^{27}$ Cf. Ibid., p. 47-53.

${ }^{28}$ Cf. CASSIRER. Ernst. Antropologia Filosofica. Mexico: Fondo de Cultura Económica, 1992, p. 45-49.

${ }^{29}$ SCHELER, M. op. cit., 2003, p. 49.

${ }^{30}$ Ibid., p. 48.

${ }^{31}$ Id. 
ser objetivo, mas somente uma ordem estruturada de atos que se realiza continuamente a si mesma ${ }^{32}$.

A expressão de Scheler - talvez fosse melhor traduzida como "puro ato" ou "pura atividade" - pretende afirmar que o espírito não é uma substância, muito menos algo "objetivo". É apenas a "reunião" de atos que se sucedem indefinidamente, sem jamais constituir algo objetivo, no dizer de Hume. O espírito não pode ser "coisificado", no dizer de Scheler; nem se pode identificar nada no espírito além dos atos em conjunto em perpétuo fluir.

Definindo o "espírito" como "pura atualidade", Scheler tem mente com isso excluir o conceito substancial de "alma" da filosofia clássica, porque "alma" comporta uma "objetivização" ou "coisificação" do espírito. No entanto, tudo o que ele fala sobre o "espírito" e suas potencialidades ou atributos, a filosofia antiga e medieval atribuía mesmo à "alma espiritual”.

d) O "espírito" comporta a independência, liberdade ou autonomia existencial frente à pressão dos impulsos vitais e frente ao meio:

Se colocarmos no ápice do conceito de espírito uma função particular de conhecimento, a espécie de conhecimento que só ele pode dar, então a determinação fundamental de um ser espiritual... é o seu desprendimento existencial do orgânico, sua liberdade, sua separabilidade ... ante os laços, a pressão e a dependência do orgânico, da "vida" e de tudo o que pertence à via ... Desta maneira, um ser "espiritual" não está mais vinculado a pulsões e ao meio ambiente. Ao contrário, ele está muito mais "livre do meio ambiente", e, como gostaríamos de denominalo, "aberto para o mundo"; um tal ser tem "mundo"33.

Dotado dessa liberdade em relação ao meio, o homem é caracterizado como o "asceta da vida": Comparando com o animal, que diz "sim" à realidade ..., o homem é o que sabe dizer "não", ele é o asceta da vida, o eterno protestador contra toda a mera realidade ${ }^{34}$. Em outras palavras, o animal sempre obedece aos seus instintos vitais, é escravo deles. O homem, pela sua liberdade, pode se contrapor aos seus instintos e assim se determinar como verdadeiro dono de seus atos, fruir da liberdade num mundo de necessidades.

e) A consciência do absoluto. Trata-se do fato que a natura humana comporta uma referência à transcendência.

${ }^{32}$ SCHELER, M. op. cit., 2003, p. 45

${ }^{33}$ Ibid., p. 36.

${ }^{34}$ Ibid., p. 53. 
"A consciência do mundo, de si próprio e de Deus formam uma unidade estrutural ilacerável - exatamente como a transcendência do objeto e da autotranscendência emergem justamente no mesmo ato" ${ }^{35}$.

A consciência do absoluto está em conexão necessária com a consciência do mundo e a consciência de si. Quer dizer, a consciência do relativo pede a consciência do absoluto.

Faz parte do "espírito" a consciência do absoluto - da transcendência ou do divino - não importa se ela é explícita e formal ou não.

Apreende-se a rigorosa necessidade essencial deste contexto que subsiste entre a consciência do mundo, a consciência do si próprio e a consciência formal de Deus - e "Deus" é apreendido aqui como um "ser que é por si mesmo", dotado com o predicado "divino", um ser que pode assumir uma miríade de locupletações as mais multicoloridas. Mas a esfera de um ser absoluto em geral, indiferentemente do fato de ela ser acessivel à vivência e ao conhecimento, pertence de maneira tão constitutiva à essência do homem quanto a sua autoconsciência ou a sua consciência do mundo ${ }^{36}$.

Scheler argumenta que a ideia de Deus surge devido à possibilidade do "nada absoluto"; ou seja, para superar a falta de sentido do ser, do mundo e da vida, o nihilismo total. O homem procura superar a ideia e o sentimento do nada, preenchendo o vazio da ausência de sentido com formas de "salvação". A primeira forma é a metafísica, que surgiu em poucos povos e tardiamente; a segunda é a que deu origem à religião, nascida de mitos criados pela inata fantasia humana para salvar o indivíduo e o grupo.

No final de sua vida, no entanto, Scheler abjura a sua cosmovisão cristã e cai numa espécie de panteísmo, muito de inspiração hegeliana, concluindo: "o homem é o único lugar do advento de Deus...”.

Precisamos rejeitar todas as ideias desse tipo (teístas) para a nossa consideração filosófica da relação do homem com o fundamento supremo; e já o precisamos porque recusamos a pressuposição teísta: um deus espiritual, pessoal e onipotente em sua espiritualidade. Para nós, a relação fundamental do homem com o fundamento do mundo reside no fato de que este fundamento se compreende e realiza no homem - que como tal, tanto como ser espiritual quanto como ser vivo, é sempre apenas um centro parcial do espirito e do ímpeto do "ser que existe por ai ". Eu digo: ele se compreende e realiza imediatamente do homem mesmo ${ }^{37}$.

As considerações de Scheler sobre a "posição do homem no cosmos" se finalizam numa receita que dilui a transcendência na imanência, do sobrenatural no natural. Pode essa atitude ser elevada a uma proposta de vida? Esse "ato de entrega" seria entrega para

\footnotetext{
${ }^{35}$ SCHELER, M. op. cit., 2003, p. 86-87.

${ }^{36}$ Ibid., p. 86

${ }^{37}$ Ibid., p. 88-89.
} 
quem, enfim, e essa "identificação pessoal” seria com quem mesmo? Segundo a proposta final de Scheler, seu humanismo reduz a um encerramento do homem no seu próprio casulo, uma conversão à sua subjetividade ("o homem é um deus que está se fazendo"). Encontrará ele em si mesmo um "Tu” para essa "identificação pessoal”, a fím de compreender e aceitar suas limitações, para obter o consolo na dor, o arrimo nas debilidades? Deverá ele ouvir unicamente a voz do seu "eu"? Definitivamente, a proposta de Scheler não mata a fome do "espírito", seu humanismo fica muito comprometido e a diferença entre o homem e o animal cai para quase nada.

\section{Referências}

CASSIRER. Ernst. Antropologia Filosofica. Mexico: Fondo de Cultura Económica, 1992.

GEHLEN, Arnold. (1940). El hombre: su naturaleza e su lugar en el mundo. 2. ed. Salamanca: Sígueme, 1980.

HARTMANN, Nicolai. Zum Problem der Realitätsgegebenheit. Berlin: PanVerlagsgesellschaft, 1931.

HEIDEGGER, M. Kant y el problema de la metafísica. Mexico: Fondo de Cultura Económica, 1986.

KANT, Immanuel. Crítica da razão pura e outros textos filosóficos; Kant, Immanuel. São Paulo: Abril Cultural, 1974.

LACROIX, Jean. Amor y persona. Madrid: Caparrós editores: 1996.

LÖWITH, Karl. De Hegel a Nietzsche. 2. ed. Buenos Aires: Editorial Sudamérica, 1974.

MOUNIER, Emmanuel. O personalismo. 3. ed. Lisboa: Martins Fontes, 1974.

NÉDONCELLE, Maurice. Persona humana y naturaleza: (estudio lógico y metafísico. Madrid: Fundación Emmanuel Mounier, 2005.

PORTMANN, Adolf. Biologie und Geist. Frankfurt: Suhrkamp, 1973.

PLESSNER, Helmuth. Die Stufen des Organischen und der Mensch; Einleitung in die philosophische Anthropologie. Berlin: De Gruyter, 1965.

ROTHACKER, Erich. Philosophische Anthropologie. Vorlesungen aus den Jahren 1953/1954. 2. ed. Bonn: Bouvier, 1966. 
SCHELER, M. A Posição do Homem no Cosmos. Título original: Die Stellung des Menschen im Cosmos de 1928. Rio de Janeiro: Ed. Forense Universitária, 2003. 